\title{
Ensinando Saúde Bucal para Deficientes Visuais Através de uma Ferramenta Web
}

\author{
Anita Maria da Rocha Fernandes ${ }^{1}$, Fabiana Oro Cericato Costa ${ }^{2}$, Ana Paula \\ Soares Fernandes Lamha ${ }^{3}$, Daniela S. Moreira ${ }^{1}$ \\ ${ }^{1}$ Curso de Ciência da Computação - UNIVALI - Florianópolis - SC - Brasil \\ ${ }^{2}$ Policlínica de São José - São José - SC - Brasil \\ ${ }^{3}$ Curso de Odontologia - UniCEUMA - São Luis - MA - Brasil \\ anita.fernandes@univali.br, fabicericato@gmail.com, \\ anapaulasflamha@gmail.com; dani.smoreira@gmail.com
}

\begin{abstract}
This paper presents a web tool OdontoVoice, as well as its application in a group of blind people. The goal of this tool is to aid blind people to take care of their dental health. The results of the tool's use aroused the interest of blind people treat oral health and showed that the tool changed the perception of blinds about dental health and contributed to improve their self esteem, since they have come to know concepts that previously don't take part of their life, such as caries and bad breath.
\end{abstract}

Resumo. Este artigo apresenta a ferramenta web OdontoVoice, bem como sua aplicação em um grupo de deficientes visuais. Tal ferramenta tem por objetivo auxiliar os indivíduos deste grupo na manutenção da saúde bucal. Os resultados obtidos mostraram que a utilização da ferramenta despertou o interesse dos deficientes visuais em tratarem da saúde bucal, bem como contribuiu para a melhoria da auto estima dos mesmos, uma vez que eles passaram a conhecer conceitos que antes não faziam parte do seu dia a dia, porém são comuns ao cotidiano das demais pessoas, como por exemplo, cárie e mal hálito.

\section{Introdução}

A deficiência visual é classificada como um tipo de deficiência física e, segundo Craft e Liebermean (2004), são considerados deficientes visuais os portadores de cegueira e os indivíduos com baixa visão. Nunes e Lomônaco (2008) consideram deficiência visual como uma limitação sensorial que abrange vários graus de acuidade visual. O Censo de 2010 revelou que $23,9 \%$ da população brasileira são portadores de deficiência visual total ou baixa visão [IBGE 2010]. E destes, 68.000 estão na educação básica e representam apenas 0,13\% dos 52,6 milhões de alunos matriculados nas instituições de ensino superior.

Apesar dos avanços significativos na área da saúde, no que tange a atenção odontológica voltada a Deficientes Visuais (DV), esta ainda é muito precária no Brasil. De acordo com Oliveira et al (2012), isto se deve a motivos tais como: poucos centros especializados para a assistência destes pacientes; um número muito restrito de 
cirurgiões dentistas que se habilitam a fazer este tipo de tratamento no setor privado; o tratamento odontológico criativo; por ser uma intervenção clínica, possui um custo muito elevado; e principalmente, a falta de educação, motivação e interesse da família em relação à saúde bucal desses indivíduos. É fato que um dos principais fatores que promovem a saúde da população é a educação. Na literatura verifica-se vários métodos educativos que são utilizados para promover a educação e a motivação dos pacientes quanto à saúde bucal, portanto, deve-se procurar, dentro dos seus limites, adaptá-los a cada situação, para que desta forma tenham uma utilidade concreta incluindo todas as camadas da sociedade. Dentre os recursos didáticos utilizados na educação especial dos DV encontra-se o livro Braille, o Sorobã (máquina de calcular), o livro falado e a informática [Cericato 2007].

De acordo com Bonatto (2003), as contribuições que a informática vem proporcionando às pessoas deficientes são valiosas, porém, sua utilização de modo efetivo esta longe de um patamar aceitável. Dentre os recursos existentes na informática para os DV citam-se os sistemas de ampliação de imagens; para pessoas com visão subnormal [Bonatti 2006]. Já as pessoas que possuem cegueira total, tem-se os sintetizadores de voz [Golin 2003]. Os recursos trazidos pelo advento da web foram fundamentais, e abriram novos paradigmas para as pessoas com deficiência, o que proporciona um espaço de troca importante para o aumento da auto-estima e da sensação de inclusão. As pessoas DV são as que enfrentam maior dificuldade no acesso a web e para que elas se sintam verdadeiramente incluídas, são utilizadas tecnologias, normalmente baseadas em síntese de voz.

No sentido de contribuir para o acesso participativo e universal do cidadão ao conhecimento, este artigo foca em uma contruibuição para a educação em saúde de Deficientes Visuais, mais especificamente em saúde bucal, fazendo com que os mesmos possam melhorar a qualidade de vida e consequentemente a auto-estima. $\mathrm{O}$ artigo apresenta a ferramenta OdontoVoice, desenvolvida para web utilizando leitor de texto que transforma o conteúdo sobre saúde bucal cadastrado em um website em áudio, possibilitando assim, uma forma de educação em saúde bucal para DV. Nas próximas seções serão apresentados os conceitos principais sobre a prática odontológica frente ao DV; a ferramenta OdontoVoice e a descrição de sua aplicação em um grupo de DV, bem como os resultados obtidos.

\section{A Educação e a Saúde Bucal de Deficientes Visuais}

Oliveira et al (2010), colocam que, devido ao fato de o paciente com necessidades especiais apresentar limitações, ele não é capaz, muitas vezes, de realizar sua própria higienização, ou a realiza de maneira inadequada e os pais ou responsáveis nem sempre se preocupam com sua saúde bucal. Segundo Rath et al (2001), a visão desempenha um papel fundamental no desenvolvimento psicomotor da criança, pois é através dela que o ser humano entra em contato com o mundo exterior, se esforça para alcançar objetos e imita os atos daqueles que estão a sua volta. Em geral, devido ao atraso na aprendizagem das atividades fisiológicas diárias, os cuidados com relação à higiene bucal de pacientes DV ficam muitas vezes comprometidos.

Outro fator agravante seria a dificuldade em procurar tratamento odontológico e a sua aceitação [Carvalho et al 2010]. Embora vários fatores biológicos sejam essenciais 
para o surgimento de muitas patologias na população, constata-se que existem fatores que são capazes de condicionar o surgimento e influenciar o ritmo de sua expansão. De acordo com Souza Filho et al (2010), dentre estes fatores destaca-se o nível sócio econômico cultural do país, bem como os padrões de cultura e tradição popular que regulam os hábitos e as condutas pessoais e coletivas.

A educação em saúde é utilizada em odontologia com o objetivo de que a população sofra mudanças no seu comportamento necessárias à prevenção, promoção e recuperação da saúde [Petry e Pretto 1999 apud Costa 2010]. Além disso, todo o processo de educação em saúde bucal deve receber uma atenção mais abrangente, na qual sejam integrados aspectos preventivos, curativos, biopsicossociais e ambientais capazes de proporcionar uma visão dinâmica de todo o processo saúde-doença, relacionado-o com a qualidade de vida. É preciso ter em mente os limites e as dificuldades do processo educativo, e que alguns programas educativos têm falhado por não considerarem que as pessoas precisam ter suas necessidades básicas atendidas para se sentirem motivadas a cuidar de sua saúde bucal [Cericato 2007].

Cericatto (2007) afirma que quanto à relação existente entre a odontologia e os DV, nota-se a necessidade de programas que sejam adaptados a eles, pois mesmo quando informados, ainda apresentam dificuldades para exercer uma higiene bucal. Rath et al (2001) afirmam que um fator importante para a educação em saúde bucal é o período em que a deficiência visual se instalou no indivíduo, uma vez que aquelas pessoas que nunca enxergaram ou que perderam a visão precocemente, não possuem conceitos visuais e, portanto, necessitam de explicações mais detalhadas para perceberem o ambiente odontológico diferentemente daquelas pessoas que vieram a perder a visão na fase adulta.

\section{A Tecnologia da Informação e a Saúde Bucal de Deficientes Visuais}

Segundo Laudon e Laudon (2007), a Tecnologia da Informação é a transformação que causou maior impacto nos setores de saúde e educação nas últimas décadas. No que se refere à área odontológica, as pesquisas na área não param, desde o que se refere a formação dos profissionais, através dos recursos que a informática aplicada a educação fornece; até as abordagens baseadas em jogos educativos que buscam estimular crianças e adolescentes à saúde bucal, passando pelos equipamentos cada vez mais sofisticados que visam auxiliar os profissionais em seus diagnósticos. No que se refere à educação em saúde bucal, vários são os exemplos de aplicação da Tecnologia da Informação (TI). Trandafilov e Rodrigues (2006) desenvolveram um ambiente virtual para estimular a prevenção e promover a saúde bucal em alunos da rede pública em séries inicias do ensino fundamental, sendo considerado pelos profissionais da área odontológica, um marco no uso de TI para educação em saúde bucal no país.

Apesar da disseminação da aplicação da TI no auxilio a educação em saúde bucal, os ambientes virtuais, os jogos digitais, bem como os simuladores, e os conteúdos disponibilizados na web sobre o assunto, não consideram a parcela da população que possui deficiência visual, foram escritos para pessoas que podem enxergar e vivenciar o as informações apresentadas na tela do computador (imagens e vídeos, por exemplo). Para tais pessoas, o recurso tecnológico mais próximo de sua realidade são os leitores de texto. Os leitores de texto poderiam ser considerados uma solução no sentido de 
disseminar o conteúdo necessário para promover a saúde bucal, porém, o conteúdo disponível para ser acessado pelos DV está disperso, escrito de uma maneira muito genérica, sem estimular o público DV. Em outras palavras, os recursos computacionais existem, porém não são aplicados de uma forma apropriada para a maioria dos DV. Não há uma linha mestra de pesquisas que foquem efetivamente em melhorar a interação de DV com os recursos computacionais.

\section{A Ferramenta OdontoVoice}

A Figura 1 apresenta a estrutura da ferramenta OdontoVoice. A ferramenta foi desenvolvida em PHP com algumas funções em Java Script, utilizando Java Applet apenas para emitir os sons das páginas. O banco de dados utilizado foi o MySQL e a interface foi organizada em HTML. O servidor que hospeda a ferramenta dispõe do Apache HTTP Server; PHP com bibliotecas para o Apache; acesso ao MySQL; e banco de dados MySQL versão 5.0, ou superior. Já a máquina do usuário deve possuir JRE 5.0 (Java Run Time Enviroment) - que contem a máquina virtual Java; navegador Firefox Mozilla 1.5; ou Microsoft Internet Explorer 6.0 ou versões superiores, teclado numérico, caixas de som multimídia, além é claro, acesso a internet.

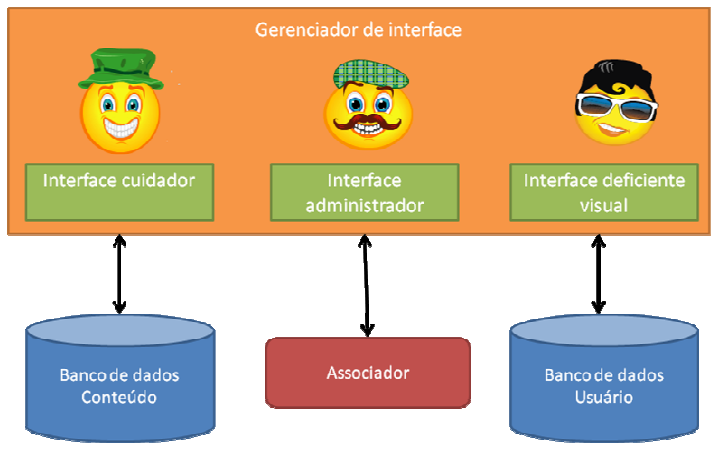

Figura 1. Estrutura da ferramenta.

Conforme ilustra a Figura 1, OdontoVoice possui um banco de dados para os conteúdos e um banco de dados para dados do usuário, uma ferramenta chamada Associador, a qual faz a ligação entre OdontoVoice e o leitor de telas (Jaws ou Dosvox). O conteúdo é cadastrado pelo administrador, que é um profissional da área de odontologia, que seleciona os temas e os conteúdos. O gerenciador de interfaces tem por objetivo controlar qual o tipo de interface deve ser apresentada. Se o usuário é um cuidador, a forma como o conteúdo é apresentado, bem como o nível de detalhamento é bem diferente da interface e conteúdo apresentado ao deficiente visual. Já o administrador tem acesso aos dois tipos de interface. Para concepção da interface foram consideradas as questões de acessibilidade na web, as quais influenciaram na escolha dos leitores de tela. O termo acessibilidade na Web, ou $e$-acessibilidade, refere-se especificamente ao componente web, que é um conjunto de páginas escritas na linguagem HTML e interligadas por links de hipertexto. A acessibilidade na web representa para o usuário o direito de acessar a rede de informações e de eliminar barreiras arquitetônicas, de disponibilidade de comunicação, de acesso físico, de equipamentos e programas adequados, de conteúdo e apresentação da informação em formatos alternativos [Nevile 2005]. 
Existem numerosas tecnologias de apoio que dão suporte a pessoas deficientes no acesso a sites. Existem desde programas de computador a dispositivos físicos que realizam esta intermediação. No caso das pessoas DV, estas tecnologias utilizam principalmente a síntese de voz para apresentar informações. Entre os programas desta categoria, estão os leitores de tela e o sistema Dosvox. Existem muitos leitores de tela disponíveis, sendo a maioria, adquirida comercialmente e de custo bastante elevado. Destacam-se o Jaws, o Virtual Vision e o NVDA. A Figura 2 ilustra a primeira tela correspondente a abertura do ambiente virtual a qual dá as boas vindas ao usuário e solicita sonoramente que o mesmo tecle "ENTER". A Figura 3 apresenta a tela onde o cuidador ou responsável pela saúde bucal do DV (por exemplo, funcionário da ACIC Associação Catarinense de Inclusão do Cego) cadastra os dados do usuário DV. Após ter sido cadastrado, o usuário é direcionado para um questionário com 24 questões que avaliam os cuidados e as práticas de saúde bucal do usuário. A Figura 4 apresenta uma das telas correspondentes às perguntas que mensuram o grau de percepção sobre cuidados em saúde bucal.

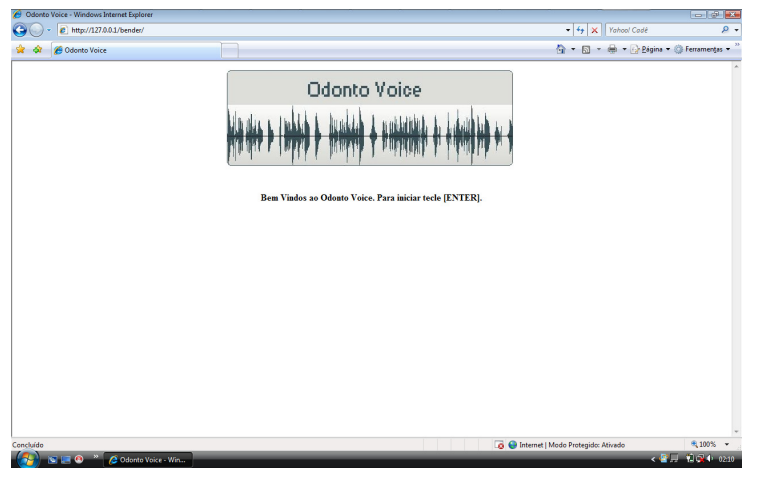

Figura 2. Tela de abertura da ferramenta.

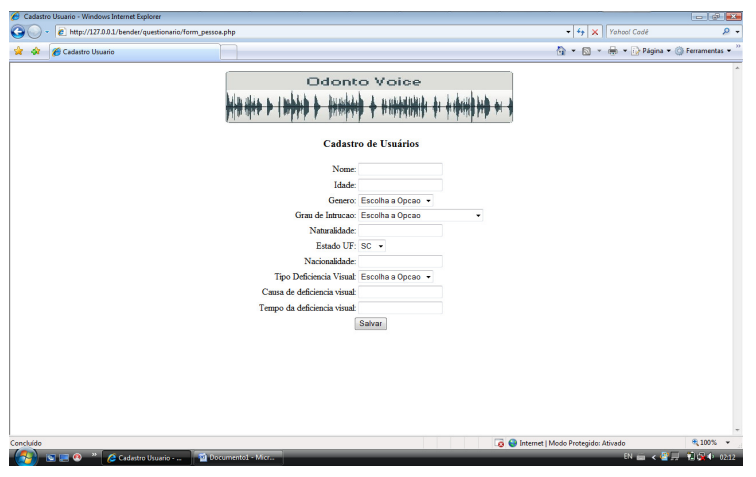

Figura 3. Tela de cadastro do usuário.

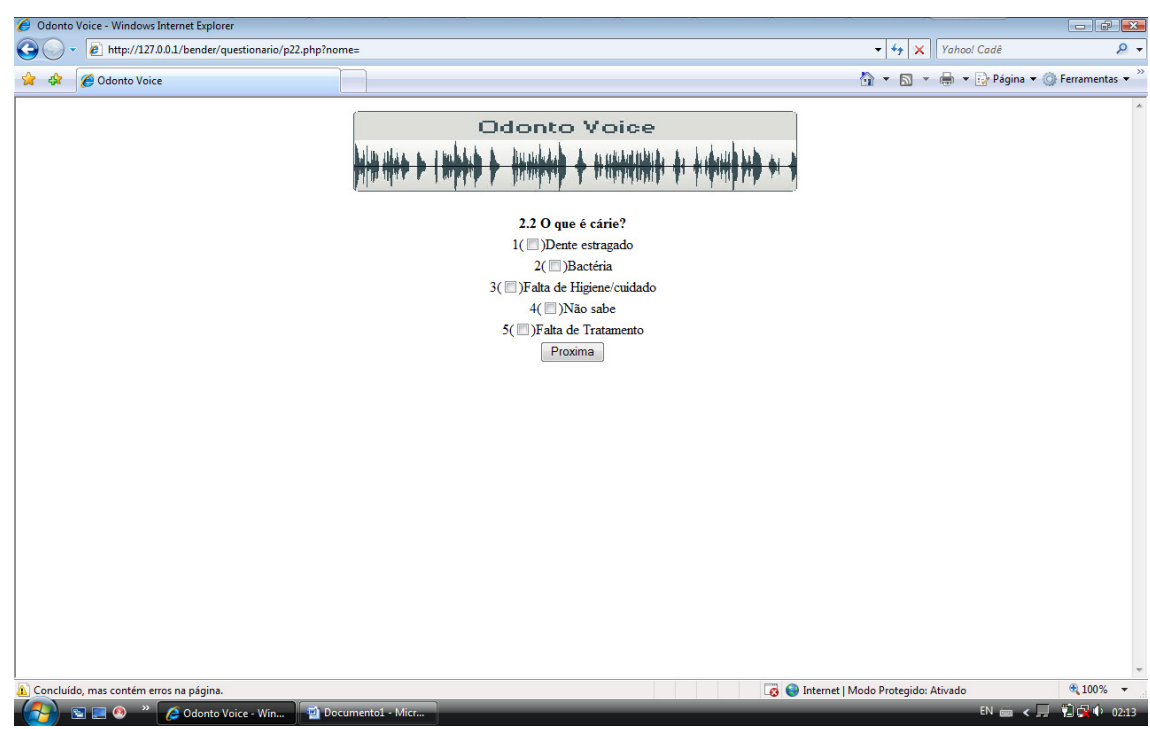

Figura 4. Tela de pergunta que mensura o grau de percepção sobre cuidados em saúde bucal.

Algumas perguntas aceitam mais de uma resposta, neste caso, é informado ao usuário sonoramente que ele pode marcar mais de uma opção. Todas as perguntas e opções de respostas são apresentadas visualmente e sonoramente. Caso o usuário 
selecione uma opção erroneamente, basta que ele pressione novamente o número do teclado correspondente a opção que ela será desmarcada. Quando a pergunta só possui uma opção de resposta, o sistema não permitirá que o usuário assinale mais de uma opção. Caso o usuário não entenda a pergunta, ou uma das opções, o som é repetido automaticamente após 15 segundos. A Figura 5 apresenta a tela correspondente a apresentação dos links. A Figura 6 apresenta a seguir uma das telas do conteúdo referente ao link 5 - Flúor

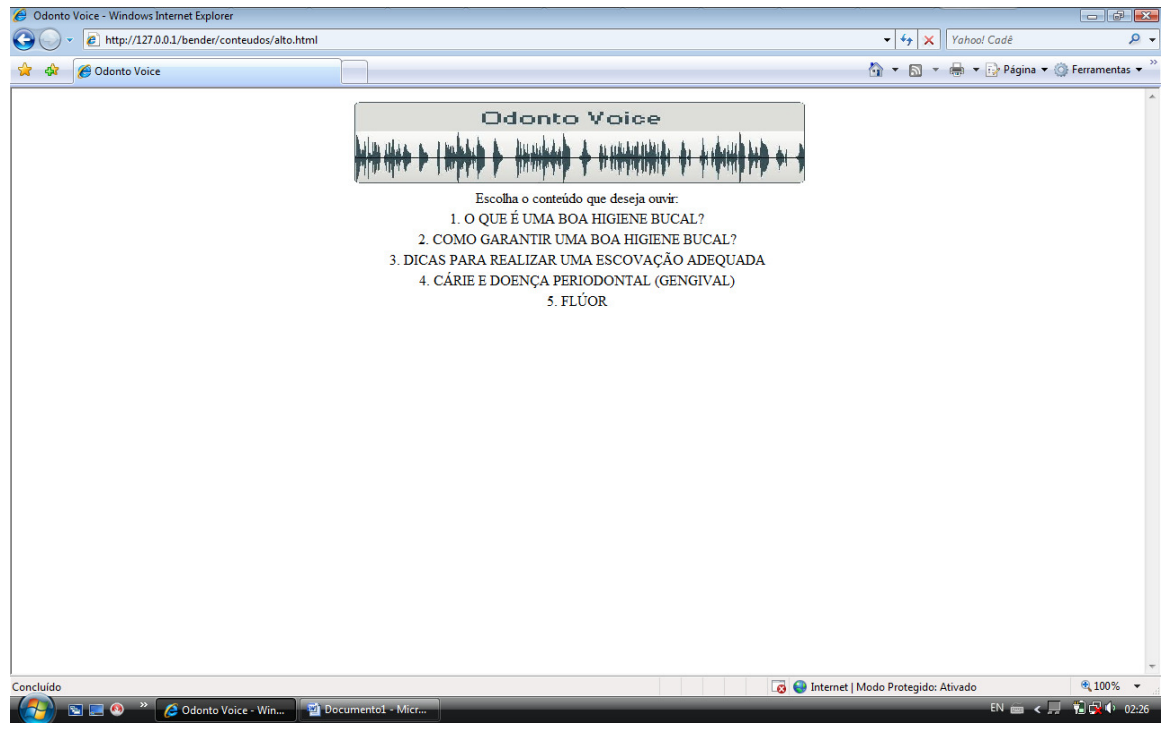

Figura 5. Tela de apresentação dos links para acessar o conteúdo desejado.

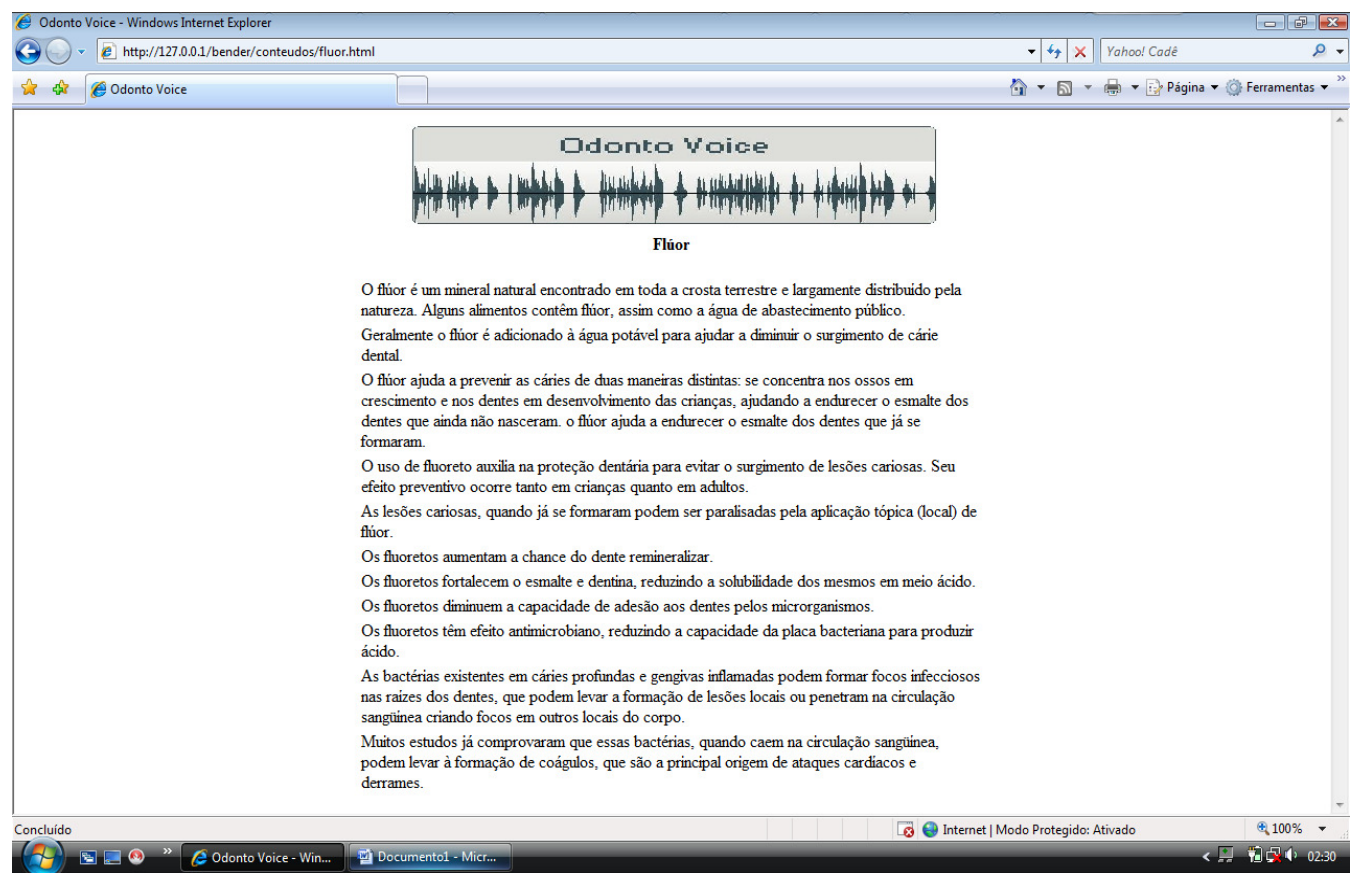

Figura 6. Tela correspondente ao conteúdo selecionado.

\section{Aplicação da Ferramenta em um Grupo de Deficientes Visuais}

Para avaliar a ferramenta como elemento motivador para o DV ter uma atenção especial a sua saúde bucal, a ferramenta foi aplicada em um grupo de deficientes visuais da 
ACIC (Associação Catarinense de Integração do Cego). O experimento teve como base todos os DV da ACIC devidamente matriculados no ano de 2009, e que aceitaram participar. No início dos trabalhos pode-se constatar que estavam regularmente matriculados 141 indivíduos portadores de cegueira total ou de baixa visão. Após a apresentação da proposta do experimento aos alunos da ACIC definidos como população alvo, verificou-se a disponibilidade dos mesmos para participar das seções, e estabeleceu-se a amostra de 54 indivíduos sendo 31 portadores de cegueira total e 23 portadores de baixa visão. $\mathrm{O}$ experimento foi realizado em várias etapas as quais serão descritas a seguir.

Primeiramente os sujeitos do estudo foram divididos em dois grupos e quatro subgrupos: Grupo A - usuários que possuíam aptidão para utilizar o computador e acessar a internet; Subgrupo A1 - usuários que possuíam aptidão para utilizar o computador e acessar a internet portadores de cegueira total. Subgrupo A2 - usuários que possuíam aptidão para utilizar o computador e acessar a internet portadores de baixa visão. Grupo B - usuários que não possuíam domínio para utilizar o computador e acessar a internet; Subgrupo B1 - usuários que não possuíam aptidão para utilizar o computador e acessar a internet portadores de cegueira total. Subgrupo B2 - usuários que não possuíam aptidão para utilizar o computador e acessar a internet portadores de baixa visão. Foram realizadas 36 visitas semanais à instituição, nas quais foi verificado o grau de percepção sobre cuidados em saúde bucal em portadores de deficiência visual.

Para os indivíduos do Grupo A - usuários que possuíam aptidão para utilizar o computador e acessar a internet as etapas do trabalho ocorreram da seguinte maneira:

- $1^{\text {a }}$ Etapa - Grau de Higiene Bucal: para verificar a capacidade de controle de placa bacteriana, bem como os padrões de higiene oral desses indivíduos foi utilizado o Índice de Controle de Placa (ICP), proposto por O’Leary, Drake e Naylor (1972).

- $2^{\text {a }}$ Etapa - Odonto Voice: após a mensuração do ICP os indivíduos foram instruídos a acessar Odonto Voice para que inicialmente respondessem um questionário constituído por três áreas temáticas: a percepção dos deficientes visuais quanto à saúde bucal, o conhecimento popular dos deficientes visuais quanto à saúde bucal e as práticas cotidianas quanto à saúde bucal. Imediatamente após o usuário responder ao questionário como já especificado no capítulo anterior o mesmo é direcionado a acessar conteúdos pré-definidos.

- $3^{\text {a }}$ Etapa - Aplicação do Questionário de Avaliação da ferramenta Odonto Voice: os indivíduos integrantes desse grupo foram convidados a responder um questionário composto de 10 questões a respeito da ferramenta Odonto Voice.

- $4^{\text {a }}$ Etapa - Reavaliação do Índice de Controle de Placa - a fim de avaliar o quanto a utilização da OdontoVoice auxiliaria na melhoria do grau de higiene bucal, após a trigésima sexta visita, foi feita uma reavaliação do ICP.

Para os indivíduos do Grupo B - usuários que não possuíam aptidão para utilizar o computador e acessar a internet as etapas do trabalho ocorreram da seguinte maneira:

- $1^{a}$ Etapa: Aplicação do Questionário: os usuários foram convidados a responder um questionário constituído por três áreas temáticas: a percepção dos deficientes visuais quanto à saúde bucal, o conhecimento popular dos deficientes visuais 
quanto à saúde bucal e as práticas cotidianas quanto à saúde bucal. A aplicação do questionário foi realizada individualmente, sendo que a pesquisadora responsável lia as questões e as opções de resposta de cada questão, integralmente, e anotava a resposta dada pelo usuário.

- $2^{\text {a }}$ Etapa: Grau de Higiene Bucal: para verificar a capacidade de controle de placa bacteriana, bem como os padrões de higiene oral desses indivíduos foi utilizado o Índice de Controle de Placa (ICP).

- $\quad 3^{\text {a }}$ Etapa: Educação em Saúde Bucal: após a realização do ICP, os indivíduos do grupo $\mathrm{B}$ receberam informações sobre a maneira correta de higienizar a boca através da utilização da elaboração de materiais pedagógicos específicos de educação em saúde bucal a esta população. Trata-se de um material confeccionado com placas de madeira, em forma de encaixe, e com diferentes superfícies para facilitar o tratamento por parte dos sujeitos.

- $4^{\text {a }}$ Etapa: Aplicação do Questionário de Avaliação do Material Pedagógico: os indivíduos integrantes desse grupo foram convidados a responder um questionário composto de 8 questões a respeito da metodologia empregada.

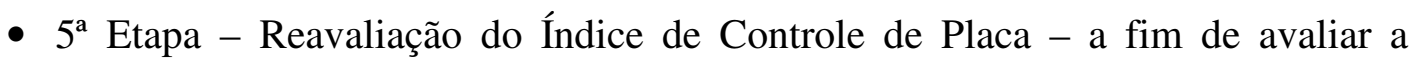
contribuição do material pedagógico na melhoria do grau de higiene bucal, após a trigésima sexta visita, foi feita uma reavaliação do ICP.

\subsection{Resultados Alcançados}

Antes de apresentar os resultados alcançados cabe descrever como os indivíduos que fizeram parte do experimento percebiam a saúde bucal. Quando questionados sobre os problemas bucais que conheciam, 46 citaram a cárie, sendo 23 do grupo Ae 23 do grupo B, 16 citaram sangramento na gengiva, sendo 8 do grupo A e 8 do grupo B, 10 citaram afta, sendo 6 do grupo A e 4 do grupo B e outros 10 citaram tártaro, sendo 4 do grupo A e 6 do grupo B. No que se refere a o que é cárie, 17 responderam que cárie seria uma bactéria, sendo 9 do grupo A e 8 do grupo B, 16 responderam que seria um dente estragado, sendo 6 do grupo A e 10 do grupo B, 14 responderam que seria a falta de higiene/cuidado, sendo 8 do grupo A e 6 do grupo B, 2 responderam que seria falta de tratamento, ambas do grupo A. Cinco pessoas responderam que não sabiam do que se tratava, sendo 2 do grupo A e 3 do grupo $\mathrm{B}$.

Quando questionados se os dentes duravam a vida toda, 30 participantes responderam que sim, sendo 14 do grupo $\mathrm{A}$ e 16 do grupo $\mathrm{B}$. Vinte e quatro responderam que não, sendo 13 do grupo A e 11 do grupo B. Quanto a necessidade de receber informações claras sobre os cuidados com a saúde bucal, 44 responderam que precisam de mais informações, sendo 23 do grupo A e 21 do grupo B. Treze indivíduos afirmaram que aprenderam a escovar os dentes com o auxilio de cuidadores (pai, mãe, familiares), sendo 8 do grupo A e 5 do grupo B; 5 aprenderam na escola, sendo 3 do grupo A e 2 do grupo B, e 20 responderam que aprenderam no dentista, sendo 9 no grupo A e 11 no grupo B; e 16 indivíduos responderam que ninguém nunca lhes ensinou a escovar os dentes, sendo 7 do grupo A e 9 do grupo B.

Para avaliar se a ferramenta OdontoVoice auxiliou na alteração da percepção dos indivíduos, utilizou-se o ICP, visto que presumiu-se que a partir do momento que a 
pessoa passa a ser instruída a respeito de um dado assunto, ela passa melhorar a sua percepção sobre tal assunto. Além disto, avaliou-se também a contribuição de um sistema computacional em relação aos métodos pedagógicos tradicionais.

Avaliando os grupos em relação ao ICP, obteve-se o seguinte resultado: o grupo A apresentou inicialmente um ICP médio de $17,85 \%$, sendo A $1=9,35 \%$ e A2 $=16,67 \%$ e um ICP médio final de $10 \%$, sendo A $1=8 \%$ e A2 $=9 \%$. Já o grupo B apresentou um ICP médio inicial de $24,62 \%$, sendo $\mathrm{B} 1=28,25 \%$ e $\mathrm{B} 2=10,10 \%$, e um ICP médio final de $19 \%$, sendo B1 $=19 \%$ e B2=8\%. Considerando que O ICP é considerado adequado se for menor ou igual a $10 \%$, observou-se que o grupo A alcançou um resultado significativo, pois chegou a um ICP adequado. Dos 27 indivíduos do grupo A, 12 apresentavam ICP inicial adequado e 15 apresentavam um ICP inicial inadequado. Ao final do experimento, o grupo A passou a ter 22 indivíduos com ICP adequado e 5 indivíduos permaneceram com ICP inadequado. Já no grupo B, no inicio havia 8 indivíduos com ICP adequado e 19 com ICP inadequado. Ao final do experimento obteve-se $16 \mathrm{com}$ ICP adequado e 11 permaneceram com ICP inadequado.

Comparando os dois métodos de ensino: OdontoVoice e matérias pedagógicos tradicionais, pode-se avaliar após a análise dos questionários respondidos pelos indivíduos dos 2 grupos, que o grupo que foi submetido aos métodos tradicionais acharam a exposição dos conteúdos cansativa. Já os que utilizaram a ferramenta, afirmaram que o fato de poderem acessar as informações na medida em que tinham vontade, e em outro local alem da ACIC, tornou a ferramenta bem atraente. Além disto, muitos indivíduos deste grupo afirmaram de maneira informal que o fato de estarem utilizando a web para aprender conteúdos que são importantes para suas vidas, os fizeram se sentir "normais". No que diz respeito a receptividade dos indivíduos em relação a ferramenta OdontoVoice, percebeu-se que 98,34\% dos indivíduos consideraram a ferramenta fácil de usar. Todos consideraram que a ferramenta apresenta uma linguagem compreensível, $81 \%$ afirmou que a utilização da ferramenta auxiliou na compreensão dos conteúdos sobre saúde bucal.

\section{Conclusões}

Com os resultados apresentados no experimento descrito neste artigo, pode-se verificar que a utilização de recursos computacionais para auxiliar deficientes visuais é extremamente relevante, porém ainda há muito a se fazer. Uma das principais melhorias a ser tratada individualmente, refere-se a qualidade do áudio e a sua taxa de transmissão na rede, a fim de tornar o processo síncrono. Neste contexto, estudos em relação à utilização de algoritmos específicos devem ser feitos, a fim de gerar áudios dinamicamente. Outro problema detectado refere-se a velocidade da internet que esta sendo utilizada. Dependendo da taxa de transmissão, a ferramenta se torna um pouco lenta. Além disso, a utilização da ferramenta em notebooks é limitada, pois a grande maioria dos notebooks não possui teclado numérico. Para estes dispositivos com ausência de teclado, faz-se necessário a aquisição de um teclado numérico USB.

Os estudos com a ferramenta OdontoVoice continuam e os problemas aqui detectados estão sendo tratados pela equipe de desenvolvimento à fim de se obter em um futuro próximo uma ferramenta robusta e que possa contribuir não só para a saúde bucal, mas para qualquer outro conteúdo instrucional que o deficiente visual necessite. 


\section{Referências}

Bonatti, F.A.S. (2006) Desenvolvimento de equipamento de auxílio à visão subnormal. Arq. Bras. Oftalmol. vol.69 n ${ }^{\circ} .2$ São Paulo Mar./Apr. 2006.

Bonatto, S. J. O. (2003). Desenvolvimento de Um Modelo de Ambiente Promotor de Inclusão de Pessoas com Deficiência Visual na Web. Dissertação (Mestrado em Eng. de Produção) - Pós-graduação em Engenharia de Produção, UFSC, Florianópolis.

Carvalho, A.C.P.; Figueira, L.C.G.; Utumi, E.R.; Oliveira, C.O.; Silva, L.P.N.; Pedron, I.G. (2010) Considerações no tratamento odontológico e periodontal do paciente deficiente visual. Rev Odontol Bras Central 2010;19(49).

Cericato, G.O. (2007). Educação em saúde bucal em portadores de necessidades especiais: um estudo de caso em deficientes visuais. Florianópolis, Dissertação de mestrado (Programa de Pós-Graduação em Odontologia). UFSC.

Costa, F.O.C. (2010). Desenvolvimento de uma Metodologia para Educação em Saúde Bucal para Deficientes Visuais Utilizando Tecnologia da Informação. Tese (Doutorado em Saúde Coletiva). Prog. Pós Grad. em Saúde Coletiva, UFSC, Fpolis.

Craft, D. H.; Liebermean, L. (2004) Deficiência visual e surdez. In: Winnick, J. P. Educação física e esportes adaptados. Barueri: Manole, 2004. p.181-205.

Golin, A.F. (2003). O trabalhador portador de deficiência visual: um estudo de caso. Dissertação (Mestrado em Engenharia da Produção). Programa de Pós-Graduação em Engenharia da Produção. Universidade Federal de Santa Catarina - UFSC.

IBGE, Censo 2000 (2000). Disponível em: http://www.ibge.gov.br/censo/. Acesso: Acesso em 20 jul 2006.

Laudon, K.C.; Laudon, J.P. (2007). Management information Systems: new approaches to organization and techonology. New Jersey: Prentice Hall.

Nevile, L. (2005). Adaptability and accessibility: a new framework. In: Conference of the Computer-Human Interaction Special Interest Group (Chisig) of Australia on ComputerHuman Interaction. ACM International Conference Proceeding Series, Canberra, Austrália, Nova York: ACM v. 122. p. 1-10.

Nunes, S.S.; Lomônaco, J.F.B. Desenvolvimento de conceitos em cegos congênitos: caminhos de aquisição do conhecimento. Revista Semestral da Associação Brasileira de Psicologia Escolar e Educacional. Vol. 12 Número 1 Janeiro/Junho 2008 _ 119-138.

Oliveira, J.B.; Silva, T.C.; Costa, D.P.T.S.; Silva, C.H.V. (2012). Sentir o sorriso: uma experiência de promoção de saúde bucal com um grupo de deficientes visuais em Recife. Odontol. Clín.-Cient., Recife, 11 (2) 151-153, abr./jun., 2012.

Rath, I.B.S. et al (2001) Atendimento odontológico para crianças portadoras de deficiência visual. Arq. Odontologia, Belo Horizonte, v.37, n.2, p.183-88, jul/dez.

Souza Filho, M.D.S. et al (2010) Avaliação da saúde bucal de deficientes visuais em Teresina-PI. Arquivos em Odontologia, Volume 45 No 02. Abril/Junho de 2010.

Trandafilov, R.D., Rodrigues, S.C.M. (2006). Ambiente Virtual Educativo para Prevenção e Promoção da Saúde Bucal no Ensino Fundamental. Anais do $X$ Congresso Brasileiro de Informática em Saúde - CBIS, Florianópolis. 